\title{
Interactivity in digital teaching of a foreign language (on the example of Don State Technical University)
}

\author{
Galina Radchenko ${ }^{1, *}$ and Svetlana Pervukhina ${ }^{1}$ \\ ${ }^{1}$ Don State Technical University, 344003, Gagarina sq., 1, Rostov-na-Donu, Russia
}

\begin{abstract}
The article discusses the issues of methods of teaching a foreign language using digital technologies, taking into account their development in the Rostov region on the basis of the Don State Technical University. Attention is focused on the creation of information and educational environment at the university and the features of such an important didactic property of digital learning as interactivity. The types of interactivity, their differentiation, functioning, and interaction in the educational process are considered in detail. The authors observe such directions of digital education as blended learning, distance learning, and mass public on-line courses. To create a digital medium, the university organized a digital portal SKIF. The authors describe this portal and its opportunities for distance teaching. The advantages of digital education in comparison with traditional ones are noted, and the problems of transition from reproductive to creative-problematic type of teaching a foreign language are considered. The authors also note usage of gamification and augmented reality in the digital educational process.
\end{abstract}

\section{Introduction}

The use of computer technology in teaching foreign languages began almost 70 years ago. The emergence of the Internet and the rapid development of mobile and cloud technologies gave an impulse to the integration of the latest technologies into the educational process both in foreign countries and in Russia. The term 'digital technologies' has appeared relatively recently. In the English-language pedagogical literature, it is used as an umbrella term that includes a variety of recently appeared communication technologies, such as cloud, mobile, smart technologies, etc., and it is used to denote traditional information and communication technologies [1].

Thus, in his article "The Use of Computers in Teaching Foreign Languages" M. Warschauer describes three main stages of using computer technologies in teaching foreign languages - behavioral, communicative and integration [2]. This direction is called Computer Assisted Language Learning, which literally means the study of foreign languages using computer technology.

\footnotetext{
*Corresponding author: rgalina@inbox.ru
} 
Today we can already observe not only mobile learning, but also consider it as an alternative to distance learning. The main trend of digital learning today is its integration into the existing system of traditional education, optimization and preservation of its basic methodological principles.

The aim of our research is to define digital education and trace the peculiarities of this education on the example of Don State Technical University (DSTU).

\section{Method}

To achieve the purpose of our research we made the following steps.

On the first stage of our research we gave a definition of a digital education and we described the digital education in the Rostov region. For digital education is still a new phenomenon, and this kind of education needs certain technologies and people who know how to exploit them. So, the situation with digital education varies from region to region, and in every educational establishment there are own spheres where digital technologies are implemented. Digital education involves traditions in the educational establishment, leaders who are able to show and to teach new techniques and technologies.

On the second stage of the research we introduced new digital projects taking place in Don State Technical University (DSTU). They represent a new point of view in education environment.

On the third stage we considered the advantages of digital teaching a foreign language in comparison with traditional teaching methods. DSTU is a flagman university in Rostovna-Donu, having technical, professional and financial basis for innovations in educational environment.

\section{Results}

\subsection{Definition of digital education (DE) and its implementation in the Rostov region}

Modern digital technologies are developing at a tremendous speed. Nowadays we witness how hospitals, catering establishments, and educational institutions are transformed into digital systems. Digitalization of education is the term coined for the process of transition to an electronic system. The transition into the electronic format is also possible for educational programs [3]. We see advantages of such transition in certain segments of higher education. They are likely to change radically not only the education system itself, but also its meaning and purpose.

Today, digital transformation has affected all areas of human activity without any exception. In the Rostov region, a decision was made to create a Regional Management Center. The regional government decree of the same name was approved on 3 July 2019, by the direction of the Government of the Rostov region № 378. The key task of the center is to ensure interdepartmental and inter-level interaction of authorities and organizations, we focus on the needs and problems of the population and organizations, their promptest solution, as well as constant optimization, improvement of existing business processes and administrative procedures.

The creation of this center makes it possible to switch to digital systems in the educational process.

The adoption of new federal state educational standards for vocational and general education in 2010-2012, professional standards of teachers of universities and schools in 2015 indicates the need for a significant restructuring of all components of the educational 
paradigm of schools and higher educational establishments. These changes are associated with increased attention to interactive forms of learning, the mandatory use of digital technologies (DT) at all stages of the learning process - from the presentation of material till the stage of its control, modeling and application of innovative teaching methods, organization and regulation of students' independent work.

Today researchers identify three types of DE in teaching at universities (Fig.1):

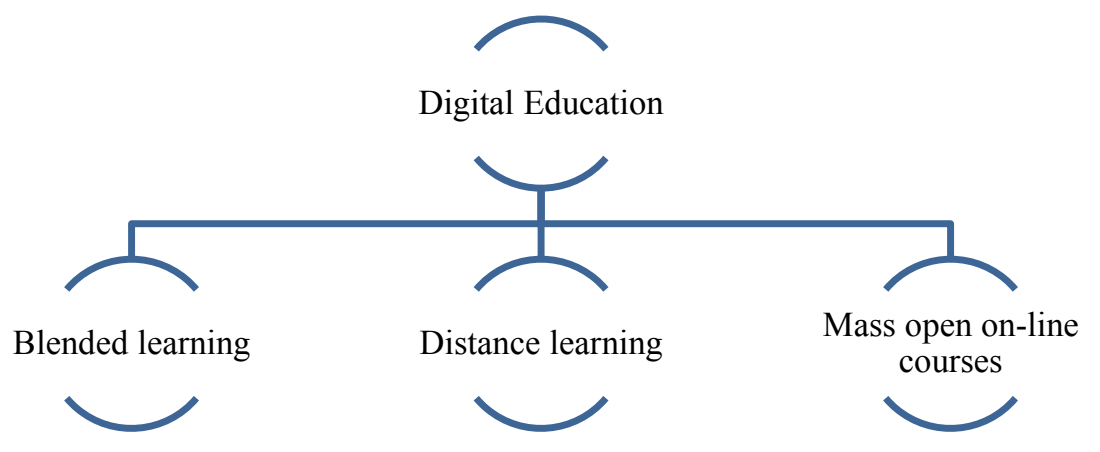

Fig. 1. Types of DE in teaching at higher educational establishments

The first type - blended learning - involves the integration of the latest technologies into the traditional learning process to increase the effectiveness of teaching various disciplines. It supposes the congregation of face-to-face and distant (on-line) education. In DSTU, this form is represented for corresponded courses. There is a data base SKIF (test.skif.donstu.ru) that has essential materials for part-time students. It serves as an electronic on-line library, and a portal for taking tests, submitting course papers, giving feedbacks. It includes questionnaires, questionnaire surveys, briefings, databases, videoconferences, wikis, glossaries, tasks, lectures, media-collections, feedbacks, debriefing, and attendance. All these options can be used in both technical and humanitarian disciplines. As for teaching foreign languages, the most usual usage is tests. Then tasks in these tests can be programmed for a limited period of time, so that no cheating is possible. After the test, the students can learn their results and see their mistakes and correct answers. Such a technique helps in final control, revision of material, and can be used for self-education. Feedback is traced on teachers' e-mail. It allows receiving a message from SKIF as long as the students 'leave a digital trace' on the portal.

Blended learning at DSTU applies a classical scheme of 70/30 ratio of on-line and offline education. It stimulates interaction and fosters an effective learning climate [4]. In the situation of the pandemic, a lot of researches find this type of learning extremely effective [5].

The second type of training - distance learning - is based on the use of DT, which allows conducting the educational process without any direct participation of the teacher, contributing to the development of skills in independent search, selection and application of information. 
The potential of SKIF to conduct blended learning and distance learning turned out to be a great help in Covid lockdown, when DSTU happened to be totally ready for switching into distance education.

The third type - mass open online courses - is represented by a new educational phenomenon based on the concept of "lifelong education" (MOOCs), which are mainly used for self-education and professional development. DSTU has got a highly professional staff who are ready to popularize scientific knowledge for its students and the interested audience outside the university.

The goal of the "Digital University" of DSTU is to introduce elements of digitalization into various areas of the university. The project provides for the development of DSTU as a multidisciplinary scientific, educational, and innovative complex; it is largely based on the technology of "big data" and machine learning in its work, which implements personified educational activities. Successful implementation of this vision will require the introduction of digitalization into all university processes: digital infrastructure, digital governance, and digital learning.

The digital university model has in its basis the modernization of the most important component in the life of any university that is the educational process. The solution to this task implies the introduction of new educational technologies, increasing the efficiency of scientific and innovative activities, training specialists and conducting scientific research that meets the needs of the digital economy. The world experience proves a positive impact of wisely-chosen technologies on the educational environment $[6,7]$.

In recent years, the popularity of on-line education and DSTU has been growing; according to the rector B.Ch. Meskhi "has an excellent base for the provision of educational services in this segment: excellent teachers, developed infrastructure, modern laboratories.

The university has a media park "Southern Region of DSTU", where there is a department of "Media communications and multimedia technologies" - thanks to these sites, we prepare original educational content that is in demand among students "(newspaper" Nashe Vremya ", 18.08.20).

\subsection{New digital projects taking place in DSTU}

Using projects in educational process helps students with necessary practice, gives them confidence in professional sphere, and fosters professional qualities [8,9]. The digital university will allow students to build individual educational trajectories: depending on their own talents and inclinations, students will be able to independently form their structure of knowledge, with which they plan to start a professional career after graduation. To assist the students with it, the university launched a pilot educational project - "Institute of Advanced Technologies School X". It started to exist in 2018. It implements a projectbased learning model aimed at developing graduates' competencies that will allow them to solve urgent technological problems, develop their own projects. All modern digital learning technologies are actively implemented at the new department of DSTU, including the Google Class service, on the platform of which the students get acquainted with educational materials of various formats, complete assignments, and receive grades. The university also has its own electronic platform edu.donstu.ru, which contains all the necessary information for students and teachers: class schedule, examination schedule, the place and mode of work (off- or on-line). This portal contains academic lists and an electronic library; there the students organize their portfolios and can order the certificates they need.

The Institute of Advanced Technologies is DSTU pilot project, on the basis of which it is intended to hone the algorithm for constructing individual educational trajectories. 100 people have been recruited, who are planning to be raised as super-engineers in 4 years' 
time. The students have passed a tough selection: they took part in design and analytical sessions, where they solved various engineering problems as part of design teams. The students of School $\mathrm{X}$ have been chosen from different departments according their high academic results, and they are given unique opportunities to make a personalized curriculum. At this stage, their teamwork skills, ability to find non-trivial solutions, leadership qualities were assessed. It is a highly-valued project for the rector of the university, B.Ch. Meskhi.

School $\mathrm{X}$ is a novel invention that is aimed at raising high-level specialists in the individual format. Such format is very unusual for Russian educational system. Education at School X follows a project-based approach, which allows the students not only to gain real experience in working at the tasks of industrial partners of the university, but also to master the extra-professional skills that are so important in the modern world. The entire educational process takes place in a multi-disciplinary format. It means that the students gain knowledge from various fields and learn to work as systems engineers who can solve complex problems using a variety of methods and technologies. They can choose the disciplinary knowledge that is useful for the implementation of their projects.

In addition, School X students study English in depth in order to be able to learn from leading practitioners from around the world, who will begin teaching them from the second year of study. We can say that information and training environment has been formed at the institute at a very professional level.

Another new project that is worth mentioning is the adaptation intensive "Freshman Navigation Days". About 4300 freshmen at the beginning of this academic year attended 1332 events of the Navigation Days, got acquainted with the city, and performed their creative tasks. This event is meant for team-building, igniting talent and creativity, and inspiring love for the place that is going to educate them.

The structure of the electronic and information environment of the university (EIE) includes the following elements:

- information and content part;

- software and hardware part;

- subjects of the educational process.

Educational programs, mobile applications, test systems for controlling knowledge and skills, and information learning resources constitute the information and content part of the EIE. It also takes into account interdisciplinary relationships and is equipped with a reference base of additional training materials. The software and hardware part consists of the software necessary to create open educational resources and conduct the educational process, as well as communication technologies that ensure interaction is understood by all participants in information objects. All participants in the educational process are able to effectively use the CT for didactic purposes.

The informational-content part of the Institute's EIE includes the following:

- Bank of pedagogical information of the university (course programs, study assignments and tests, term papers and theses, methodological developments and manuals, video collections, webinar materials);

- Scientific and pedagogical library of the institute;

- Open training resources (massive open on-line courses, websites and applications of professionals in the field of teaching foreign languages, websites and applications of professional communities and publishers, etc.);

- Scientific and methodological materials of conferences, round tables, methodical seminars;

- Official information of higher education authorities;

- Electronic periodicals of DSTU. 
It should be noted that EIE is a kind of source of educational and methodological knowledge, a highly structured environment for organizing various forms of independent cognitive activity and is formed, as a rule, either in the Internet or based on professionally developed learning management systems (LMS). Working with LMS, teachers should pay special attention to explaining to students how to organize their profiles [10]. This environment is open to both teachers and students to have a feedback.

\subsection{Advantages of digital teaching a foreign language in comparison with traditional teaching methods}

With the development of mobile technologies, such a concept as a mobile learning environment has appeared. Many scientists today identify the so-called social aspects of mobile technologies, which allow creating a special model of mobile learning, built on the theory of L. Vygotsky, which prioritizes the importance of dialogue in the educational context. Involvement, presence and freedom of action are considered as the main didactic properties of mobile technologies that contribute to the creation of an interactive learning environment [11]. The presence in the above-mentioned research means interaction, which is divided into two types: cognitive (student-educational material), and social (studentstudent).

There is no doubt that the use of multimedia programs and resources in teaching foreign languages has a number of undoubted advantages, since students can not only be in a natural atmosphere for learning a language, but also simultaneously see, hear and speak, that is, combination of all four types of speech activity in one task [12].

Digital technologies in teaching a foreign language make it possible not only to observe what is happening on a computer monitor, but also to actively participate in the learning process. This property of the DT is called interactivity.

Traditionally, interactivity is understood as the interaction through direct contact. In teaching with the use of DT, interactivity is the ability of the user to actively interact with the information carrier, to select it at their own discretion, to change the pace of material presentation [13]. Interaction between people and software system is different from the dialogue and involves the exchange of text commands and responses giving way for collaborative creativity [14]. It presupposes the implementation of more advanced means of dialogue (for example, the ability to ask questions in a conditioned form using an obligatory keyword, or with a condition of making use of a certain set of symbols), while providing the ability to select options for the content of educational material, mode of operation.

Interactivity is a fairly broad concept, which should not be limited only as the possibility of communication between people. Interactivity has various forms of implementation, such as follows:

- interaction among participants in the educational process through various types of electronic communication (feedback);

- creation of Open Educational Resources (OER) by means of the proposed components (templates, forms, graphic drawings, etc.);

- active participation of students in the process and order of completion of on-line tasks and tests;

- implementation of self-control / control over the performance of tasks using the proposed forms of answers: input of selective answers, calculated answers, graphic information, analytical expressions in a free form of recording.

Obviously, interactivity is possible when the student has the freedom to choose educational actions. This gives a student an active position in the information society and is a kind of way of individual self-realization, for it strengthens the thinking processes, contributes to a more effective understanding and assimilation of educational information. 
Thus, interactivity is the ability of a person to actively influence the content and thematic focus of a computer program or on-line resources, as well as the ability to communicate, expressing his or her opinion and learning the opinion of the people they communicate with.

Interactivity, being a key property of the DT in the educational process, contributes to the implementation of the following:

- the ability to transmit information through various types of electronic communication, such as forums, chats, teleconferences, message boards, etc.;

- the possibility of maintaining favorable conditions for the educational process, organizing demonstrations, independent work, and the succession of knowledge;

- the possibility of changing or adding information;

- the ability to create something or find a solution to a problem based on the proposed material.

Taking all above-mentioned into consideration, we can say that there are several types of interactivity in the educational process. They are as follows:

- the interactivity of the feedback provides an opportunity to ask a question on a problem of interest and get an answer. It gives the chance to control the process of mastering the material;

- temporary interactivity allows the student to independently determine the beginning, duration of the educational process and the speed of headway in the educational material;

- successive interactivity allows the students to freely determine the sequence of information fragments;

- meaningful interactivity allows the student to change, supplement or reduce the amount of meaningful information;

- creative interactivity is evident when the students create their own product of creative activity, such as a web project, their own website, electronic tests and exercises, etc.

Let us consider in more detail the interactivity of the feedback, which, in our opinion, provides the greatest efficiency of educational activities for mastering a foreign language. There can be two types of feedback in digital education. The first type comprises interaction between a student and a computer. In this case, information comes from a particular training program or mobile application included in the educational process, in response to the student's actions. Such feedback is characterized by efficiency, it enables the learner to make a conscious conclusion about the success or error of educational activity. It encourages students to reflect being an incentive for further action, and helps to evaluate and correct the results obtained. A.A. Korenev scrutinizes types of feedback in [15], seeing a computer-assisted feedback as an indirect one. It is very convenient from the point of view of flexibility in time. A.A. Korenev underlines that a lot of teachers try to make their computer comments resembling interpersonal communication [15].

The second type of feedback is the reaction of the teacher or other participants in the educational process (native speakers, project partners, etc.) to the student's activities. It can be both operational (done at once) and delayed (done within a period of time), but only to a certain extent. In the conditions of telecommunication interaction, when the non-verbal communication channels of the participants in the educational process are not used, it is necessary to pay special attention to the timeliness of this connection, its constructive and positive attitude. When organizing project activities, it is an important task for project managers on both sides to provide prompt feedback as a reaction to the results of the partners' activities. Systematically and rationally organized feedback when completing assignments is extremely important, since it contributes to the formation of a stable positive motivation for students' learning activities.

The first type of feedback interactivity or evaluative feedback (usually used in computer tests and mobile applications) has the following levels of implementation: 
- the first level is a statement of the incorrect result of the decision without analyzing the error and without providing any recommendations;

- the second level is a statement of the wrong result of the decision without analyzing the mistake made, but with the general recommendations;

- the third level of feedback is a statement of an incorrect result and the specific recommendations for providing the correct solution, and in some cases also an analysis of the mistake made.

The use of a computer for the purpose of assessing knowledge can significantly increase the objectivity of control. Subjectivity in the assessment of knowledge, due to the lack of clear assessment criteria, is in the practice of universities with the traditional method of knowledge control. Subjectivity is also manifested due to purely psychological factors. In practice of teaching foreign languages, the control procedure with the help of a computer can take into account time parameters when assessing the quality of the task, which is extremely important for objectively while establishing the level of proficiency in a foreign language. It involves not only checking a certain amount of knowledge of the grammatical structure and lexical composition of the studied language in students, but also the assessment of the formation of the relevant skills and abilities. In addition, computer programs allow students to compare the newly achieved results with the previous ones, and to keep statistics of errors.

The analysis of statistical data makes it possible to judge the level of mastery of language skills. Trainees are clearly convinced of their success, and confirmation of success stimulates their further self-improvement. According to the majority of scientists, the dialogue with a computer in this case must be built in accordance with the psychological principles for communication, which should take place in the most natural way, resemble human communication, and cause neither anxiety nor tension.

The second type of feedback interactivity is often considered as one of the means of intensifying the process of learning a foreign language. The communicative function of language is known to be one of the most important ones. An essential condition for proficiency in a foreign language is extensive communication in it, i.e. how often the student uses a foreign language in class. It is difficult to achieve high communication density in the classroom without a context of natural communication. Modern teaching experience shows that the use of DT allows partial ensuring the student's immersion in the language environment. Working on the Internet, where most of the sites are presented in English, participating in conferences and forums, students have a significant increase in the need for understanding texts in a foreign language without translating them into their mother tongue. In addition, active communicative interaction of participants in the educational process contributes to the development of methods of cognition, skills of interaction in a group, the ability to develop their own point of view, and tolerance in accepting the positions of the others.

Thus, the use of DT to ensure the interaction of participants in the process of learning foreign languages contributes to the following aspects:

- development of communicative competence;

- fostering of personality and its creative potential;

- practise of group work skills;

- creating a positive emotional atmosphere.

The main direction of development of the modern education system today is the system integration of DT into the educational process. The main thing is not "reading" with the help of a computer or mobile device the whole course or its fragments and control of what has been learned, but a higher level of representation in the educational process of the object to be mastered, the transition from a descriptive representation of this object to 
modeling its essential properties, the use of gamification elements, the creation of so-called augmented reality.

Today, for higher education, the task of using digital technologies for modeling professionally is of paramount importance.

\section{Discussion}

Digital technologies are part and parcel of contemporary higher education. It offers a lot of opportunities in acquiring cognitive knowledge. It serves for the purpose of intensification of education. The variety of types of DE can give students a chance to optimize their educational trajectory and choose the most appropriate option for them.

Nevertheless, there are some opponents who point out an emotional component of education that is also essential, but it is missed in DT. The authors stand for a balanced position of supplementing the digital education with project work. Surely, personal communication has its peculiarities that digital education unfortunately lacks. That means that DT should always be supplemented with something with a human touch. Navigation projects, mingling activities, extra-curriculum work seems to be a reliable solution in this case. The experience of DSTU curriculum and extra-curriculum activities reflect wellbalanced ratio in this respect.

The findings of this research prove that the drawbacks of digitalization can be annihilated by project work that has evident advantages for further net-working and teambuilding skills, as well as people skills.

\section{References}

1. G. Dudeney, N. Hocklay, M. Pegrum, Digital Literacies. Pearson Education LTD. (2013)

2. M. Warschauer, Language and the Digital Divide. The Encyclopedia of Applied Linguistics

http//onlinelibrary.wiley.com./doi//10/1002/9781405198431.wbeal0602/abstract (Last accessed 22.07.2020)

3. E. Fleaca, R. D. Stanciu, Digital-age Learning and Business Engineering Education - a Pilot Study on Students' E-skills. Procedia Manufacturing, 32, 1051-1057 (2019) doi:10.1016/j.promfg.2019.02.320

4. R. Boelens, B. De Wever, M. Voet, Four key challenges to the design of blended learning: A systematic literature review. Educational Research Review, 22, 1-18 (2017) doi:10.1016/j.edurev.2017.06.001

5. T. Jowsey, G. Foster, P. Cooper-Ioelu, S. Jacobs, Blended learning via distance in preregistration nursing education: A scoping review. Nurse Education in Practice, 44 (2020). doi:10.1016/j.nepr.2020.102775

6. R. P. Lima, L. M. Passerino, R. V. B. Henriques, M. Bercht, Asistranto: An Assistive Educational Platform for Promotion of Interest in Autistic Children. Procedia Computer Science, 160, 385-393 (2019) https://doi.org/10.1016/j.procs.2019.11.076

7. I. Golitsyna, Educational Process in Electronic Information-educational Environment. Procedia - Social and Behavioral Sciences, 237, 939-944 (2017) doi:10.1016/j.sbspro.2017.02.132

8. A. Adam, G. Prostean, A. Badea, O. Prostean, Knowledge Transfer in Educational Projects. Procedia - Social and Behavioral Sciences, 191, 1460-1466 (2015) doi:10.1016/j.sbspro.2015.04.346 
9. H. Karimi, H. Taghaddos, The influence of craft workers' educational attainment and experience level in fatal injuries prevention in construction projects. Safety Science, 117, 417-427 (2019) doi:10.1016/j.ssci.2019.04.022

10. A. H. Duina, J. Tham, The Current State of Analytics: Implications for Learning Management System (LMS) Use in Writing Pedagogy. Computers and Composition. 55, 102544 (2020) https://doi.org/10.1016/j.compcom.2020.102544

11. A. Hafeez-Baig, R. Gururajan, P. Danaher, Transforming the practice of mobile learning: Promoting pedagogical innovation through educational principles and strategies that work. Innovative mobile learning: Teaching and Technologies. New York (2009) DOI: 10.4018/978-1-60566-062-2.ch002

12. A. Bilyalova, ICT in Teaching a Foreign Language in High School. Procedia - Social and Behavioral Sciences, 237, 175-181 (2017) doi:10.1016/j.sbspro.2017.02.060

13. M. Nakevska, A. van der Sanden, M. Funk, J. Hu, M. Rauterberg, Interactive storytelling in a mixed reality environment: The effects of interactivity on user experiences. Entertainment Computing, 21, 97-104 (2017) doi:10.1016/j.entcom.2017.01.001

14. M. Pifarre, Using interactive technologies to [promote a dialogic space for creating collaboratively: A study in secondary education. Thinking Skills and Creativity, 32, 116 (2019) doi:10.1016/j.tsc2019.01.004.

15. A. A. Korenev, Feedback in learning, teaching and educational communication. Rhema, 2, 112-126 (2018) 